\title{
IMMUNE RESPONSE TO GUT ESCHERICHIA COLI AND SUSCEPTIBILITY TO ADJUVANT ARTHRITIS IN THE RATS
}

\author{
Vesna KovaČEvić-Jovanović*, TAtJana Miletić, Stanislava StanojeVić, \\ KATARINA MitiĆ and MIRJANA DIMITRIJEVIĆ \\ Immunology Research Center, Institute of Virology, \\ Vaccines and Sera "Torlak", Belgrade, Serbia
}

(Received: 3 July 2014; accepted: 20 September 2014)

\begin{abstract}
We have investigated the humoral immune response to antigens of predominant gut aerobic bacterial strains (i.e. Escherichia coli) over the course of adjuvant arthritis and oil-induced arthritis in two inbred rat strains: Dark Agouti (DA) and Albino Oxford (AO). We report the presence of antibodies specific to proteins of $E$. coli in molecular weight range between $20-30 \mathrm{kDa}$ in sera of diseased DA rats, and the absence of these antibodies in the sera of AO rats. In DA rats, CFA and IFA provoked a stronger antibody response to $E$. coli, especially of the $\operatorname{IgG} 2 \mathrm{~b}$ antibody class. Intramuscular administration of $E$. coli preceding the adjuvant arthritis induction had no effect on the development and course of disease, as well as on the activation of $\mathrm{T}$ cells in the draining inguinal lymph nodes. Higher serum levels of natural and induced $\operatorname{Ig} \mathrm{A}$ antibodies, combined with a higher $\mathrm{CD} 3{ }^{+} \mathrm{CD} 26^{+}$cell percentage were found in $\mathrm{AO}$ rats. The observed correlation between the serologic response to commensal flora and rats' genetic background as a defining factor for arthritis susceptibility may contribute to the process of creating a favorable (or less favorable) milieu for arthritis development.
\end{abstract}

Keywords: adjuvant arthritis, commensal bacteria, E. coli, humoral immune response, rat strains

\section{Introduction}

Autoimmune diseases are multifactorial in their etiology, therefore a myriad of factors must be considered when investigating the sensitivity/resistance to a specific autoimmune disease. Although it was shown that multiple genes contribute to rheumatoid arthritis (RA) susceptibility [1-4], it is believed that a combination of a specific genetic background and some environmental factors are

* Corresponding author; E-mail: vkovacevic@torlak.rs 
required for the disease onset. The prevailing hypothesis involves the role of microbes and infection as possible factors that could initiate the autoimmune process in genetically predisposed individuals $[5,6]$. In particular, numerous data indicate involvement of commensal microflora in the ethiopathogenesis of RA [7-9].

Adjuvant arthritis represents an animal model for rheumatoid arthritis, and can be induced in Dark Agouti (DA), unlike Albino Oxford (AO) strain [10]. We have previously shown that these rat strains show different potential to produce reactive oxygen species [11] and specific antibodies [12] in response to commensal bacteria.

Our present study investigates if specific host immune response to commensal bacteria could account for the differences in the development/course of arthritis observed in DA and AO rat strains. DA rats, unlike other rat strains, besides being sensitive to the induction of AA by Complete Freund-s adjuvant (CFA, containing Mycobacterium antigens), also develop arthritis following injection of adjuvant oils without inclusion of Mycobacterium tuberculosis cell walls [13]. Hence, the current study examined humoral immune response to antigens of predominant aerobic bacterial strains identified in gastrointestinal flora of DA and AO rat strains over the course of adjuvant arthritis (AA, induced by CFA) and oil-induced arthritis (OIA, induced by incomplete Freund-s adjuvant, IFA). It appears that the predominant Gram-negative facultative aerobe in both rat strains is Escherichia coli, while we isolated Proteus mirabilis only from DA rats gut flora. In addition, second arm of our experiment examined whether the manipulation of immune response to the intestinal flora could influence the disease onset and development. In this regard animals were pre-immunized with their own bacterial intestinal flora isolate (i.e. E. coli) followed by the induction of adjuvant arthritis. We then determined the levels of antibodies of the specific $\operatorname{IgM}, \operatorname{IgG} 2 \mathrm{a}, \operatorname{IgG} 2 \mathrm{~b}$ and $\operatorname{IgA}$ to intramuscularly encountered intestinal bacterial species. In addition, total number of $\mathrm{CD}^{+}$and $\mathrm{CD}^{+} \mathrm{CD} 26^{+}$cells in inguinal lymph nodes, as a primarily drainage site after AA/OIA induction, was also studied.

\section{Materials and Methods}

\section{Animals}

Five-month-old male rats of two inbred strains, DA $(n=40)$ and AO $(n=40)$ were used in experiments. DA and AO rats were derived from our laboratory's inhouse breeding colony. Animals were housed in identical conventional envi- 
ronments in standard polycarbonate cages, with free access to food pellets and tap water. With except to bedding sterilization, no special treatment (i.e. autoclaving, irradiation, sterilization) of the food, water, or cages for these rats was used. The rooms were maintained at 20 to $23{ }^{\circ} \mathrm{C}$ at humidity ranging $40 \%$ to $70 \%$, and under 12:12-h light:dark cycle. The experimental protocols and all procedures with animals and their care were approved by Experimental Animal Committee of the Institute of virology, vaccines and sera "Torlak", and were in accordance with principles declared in Directive 2010/63/EU of the European Parliament and of the Council from 22 September 2010 on the protection of animals used for scientific purposes (revising Directive 86/609/EEC).

\section{Experimental design}

Experiment 1. DA $(\mathrm{n}=5)$ and $\mathrm{AO}(\mathrm{n}=5)$ rats were immunized with CFA or IFA on day 0 , and daily examined for the appearance of clinical signs of arthritis until day 42 . Serum samples obtained on day 14 and day 42 were tested for the presence of anti-E. coli IgG antibodies by immunoblotting.

Experiment 2. Rats were intramuscularly pre-immunized with three doses of $E$. coli, each containing $5 \times 10^{8}$ bacterial cells, on day -21 , day -14 and day 0 and afterwards immunized with CFA or IFA (day 0). The rats of both AO and DA strains were immunized with their own bacterial antigens, i.e. E. coli. The number of rats was 6 per group.

Serum levels of anti-E. coli $\operatorname{IgM}, \operatorname{IgG} 2 \mathrm{a}, \operatorname{IgG} 2 \mathrm{~b}$ and $\operatorname{IgA}$ antibodies on day 0 , day 7 and day 21 were examined by ELISA. The percentages of $\mathrm{CD}^{+} \mathrm{CD}_{2} 6^{+}$ lymphocytes in inguinal lymph nodes of immunized rats (day 21) and non-immunized rats were determined by flow cytometry. Experimental design is given in Table I.

\section{Induction and assessment of arthritis}

In order to induce AA, rats were immunized with a single $50 \mu 1$ intradermal injection of CFA (paraffin oil $8.5 \mathrm{ml}$ and Arlacel A $1.5 \mathrm{ml}$, containing $6 \mathrm{mg} / \mathrm{ml}$ of Mycobacterium bovis, French 1173P2) in the basis of the tail. OIA was induced with a single $50 \mu \mathrm{l}$ intradermal injection of IFA (paraffin oil $8.5 \mathrm{ml}$ and Arlacel A $1.5 \mathrm{ml}$ ) at the base of the tail.

Animals were daily scored for clinical signs of arthritis according to scale from 0 to 16, with each of four paws being scored from 0 to 4 as follows: $0=$ no arthritic changes; $1=$ oedema and/or arthritic nodules on one finger; $2=$ oedema 
Table 1. Experimental design

\begin{tabular}{|c|c|c|c|c|c|}
\hline \multicolumn{6}{|c|}{ Experiment 1} \\
\hline & & Day 0 & & Day 14 & Day 42 \\
\hline & & $\begin{array}{c}\text { Immunization }^{\mathrm{a}} \\
\text { CFA } \\
\text { IFA }\end{array}$ & & $\begin{array}{c}\text { Serum } \\
\text { (Western blot) }\end{array}$ & $\begin{array}{c}\text { Serum } \\
\text { (Western blot) }\end{array}$ \\
\hline \multicolumn{6}{|c|}{ Experiment 2} \\
\hline Day 21 & Day 14 & Day 0 & & Day 7 & Day 21 \\
\hline $\begin{array}{c}\text { Immunization } \\
\text { E. coli } \\
\text { E. coli } \\
/ \\
/ \\
/\end{array}$ & $\begin{array}{c}\text { Immunization } \\
\text { E. coli } \\
\text { E. coli } \\
/ \\
/ \\
/\end{array}$ & $\begin{array}{c}\text { Immunization }^{\mathrm{b}} \\
\text { E. coli/CFA } \\
\text { E. coli/IFA } \\
\text { CFA } \\
\text { IFA } \\
\text { Non-immunized }\end{array}$ & $\begin{array}{c}\text { Serum } \\
\text { (ELISA) }\end{array}$ & $\begin{array}{l}\text { Serum } \\
\text { (ELISA) }\end{array}$ & $\begin{array}{c}\text { Serum } \\
\text { (ELISA) } \\
\& \\
\text { Lymph node cells } \\
\text { (Flow cytometry) }\end{array}$ \\
\hline
\end{tabular}

a For each rat strain the number of animals per group was 5 (total number of animals: DA, $\mathrm{n}=10 ; \mathrm{AO}, \mathrm{n}=10$ ).

b For each rat strain the number of animals per group was 6 (total number of animals including non-immunized rats which were used as a control for flow cytometry analyses of lymph node cells: DA, $n=30 ; \mathrm{AO}, \mathrm{n}=30$ ).

and/or arthritic nodules on two fingers; $3=$ oedema and/or arthritic nodules on three fingers; $4=$ oedema and/or arthritic nodules on all fingers [14].

\section{Bacterial preparations}

Bacterial species were isolated from stool specimens collected from AO and DA rats. Fecal samples were collected from healthy adult rats and cultured using different agar plates (MacConcey agar, Endo agar) under the aerobic conditions, at $37^{\circ} \mathrm{C}$ for $24 \mathrm{~h}$. Well-isolated colonies were selected randomly from the predominant flora and identified using the Gram-staining and morphological characteristics, as well as the biochemical tests and a rapid identification system (ID-32A, API Biomerieux, Marcy l'Etoile, France). E. coli was identified as a predominant aerobic flora in both DA and AO rats. E. coli was grown aerobically for $24 \mathrm{~h}$. The bacteria were harvested at stationary growth phase, washed with sterile phosphate-buffered saline (PBS) (8,000 rpm for $20 \mathrm{~min})$, and resuspended in PBS. The estimated number of bacteria in the suspension was determined by reading the optical density at $580 \mathrm{~nm}$ and extrapolating the value using a standard curve. 
Preparation of bacterial protein extract

Following the centrifugation of bacterial culture suspension $(8,000 \mathrm{rpm}$ for $20 \mathrm{~min}$ ), $1 \mathrm{~g}$ of bacterial cells pellet was homogenized on ice with the addition of $6 \mathrm{ml}$ of extraction buffer (5\% SDS, 5\% 2-merkaptoethanol, $20 \mathrm{mM}$ Tris, 20 mM Glycin, $2 \mathrm{mM} \mathrm{Na}$ EDTA, pH 6.8). The proteolysis was prevented by addition of protease inhibitor cocktail for mammalian tissues, P 8340 (104 mM AEBSF, $80 \mu \mathrm{M}$ Aprotinin, $2 \mathrm{mM}$ Leupeptin, $4 \mathrm{mM}$ Bestatin, $1.5 \mathrm{mM}$ Pepstatin, $1.4 \mathrm{mM}$ E-64, Sigma-Aldrich Chemie Taufkirchen, Germany) as well as $0.2 \mathrm{M}$ phenylmethylsulphonyl fluoride. Homogenized bacteria were centrifuged at 16,000 rpm for $15 \mathrm{~min}$, at $4{ }^{\circ} \mathrm{C}$; the supernatants were filtered through $0.45 \mu \mathrm{m}$ filters, aliquoted into criotubes and stored at $-80{ }^{\circ} \mathrm{C}$ until use.

Preparation of bacterial cell suspensions

The bacteria were killed by formalin addition (at $0.5 \% \mathrm{v} / \mathrm{v}$ final concentration), and the suspension was held at $35^{\circ} \mathrm{C}$ for more than $48 \mathrm{~h}$. Cells were then washed three times with PBS to remove the formaldehyde, resuspended at the same density in sterile PBS $/ 0.25 \%$ phenol and stored at $4{ }^{\circ} \mathrm{C}$ until use. The efficacy of killing of the bacteria in the suspensions was confirmed by sterility test. If no bacterial growth was detected, the formalin-inactivated bacteria were used as antigens for vaccines formulation and ELISA.

\section{SDS-PAGE and Western-blot}

The bacterial cells protein extracts were subjected to vertical SDS-PAGE according to the method of Laemmli [15] using 9\% separating and 4\% concentrating gel (0.75 mm width) on "Mini Protean II" system (BioRad Laboratories, Richmond, CA, USA). Gel polymerization was induced by ammoniumpersulphate (Pharmacia, Uppsala, Sweden) and tetramethylethylenediamine (Serva, Heidelberg, Germany), and the gels were blotted to nitrocellulose membranes. Molecular weight protein standards were obtained from BioRad Laboratories, Richmond, CA, USA (phosphorylase B, 94 kDa; bovine serum albumin, $67 \mathrm{kDa}$; ovalbumin, $43 \mathrm{kDa}$; carbon anhydrase, $30 \mathrm{kDa}$; soy-bean trypsin inhibitor, 21.1 $\mathrm{kDa} ; \alpha$-lactoalbumin, $14.4 \mathrm{kDa}$ ). Electrophoresis started with an initial voltage of $30 \mathrm{~V}$ and next voltage step was $200 \mathrm{mV}$. The total time of electrophoresis was 30 minutes. The proteins were detected by Coomassie Brilliant Blue staining. 
Electroforetically separated bacterial proteins were electrotransferred to nitrocellulose paper NC 2 (pore size of $0.2 \mu \mathrm{m}$, Serva, Heidelberg, Germany) as described elsewhere [16] using $1 \mathrm{~mA} / \mathrm{cm}^{2}$ electricity for 1 hour $20 \mathrm{~min}$ at room temperature. Nitrocellulose membranes were incubated in blocking buffer containing $1.5 \%$ skim milk (Sigma, St Louis, MO, USA) in PBS for 1 hour at $37{ }^{\circ} \mathrm{C}$, followed by washing with $0.05 \%$ Tween 20 in PBS and incubation with rats sera diluted 1:50 in 1\% bovine serum albumin (BSA), 0.1\% Tween 20 in PBS for 1 hour at room temperature. After washing, the membranes were incubated with the secondary antibody, anti-rat IgG-alkaline phosphatase (Sigma, St Louis, MO, USA) for 1 hour at room temperature and stained by addition of the substrate 5-bromo-4-chloro-3-indolyl phosphate/nitroblue tetrazolium (Sigma, St Louis, MO, USA). The reaction was stopped with the distilled water and blots were dried at room temperature and photographed.

\section{ELISA}

Formalin-inactivated bacterial cells (E. coli) were adsorbed separately to microtiter plates, using $50 \mu 1$ per well at the concentration of $1 \times 10^{8}$ bacterial cells per $\mathrm{ml}$. After one centrifugal cycle $(1,700 \mathrm{rpm}$ for $15 \mathrm{~min})$ and an additional incubation at $37{ }^{\circ} \mathrm{C}$ for 1 hour, the plates were washed and saturated with $200 \mu 1 /$ well of $1 \% \mathrm{BSA} / \mathrm{PBS}$. The sera were diluted in $1 \% \mathrm{BSA} / \mathrm{PBS}$ and incubated overnight at $4{ }^{\circ} \mathrm{C}$. The binding of rat serum antibacterial antibodies was detected using the secondary antibodies specific for rat Ig individual isotypes, labeled with biotin. Extravidine-peroxidase and substrate $o$-phenylene diamine (Sigma, St Louis, MO, USA) were used for detection. The optical density (OD) was measured photometrically at 492/620 nm. For the anti-bacterial IgM, IgG2a and IgG2b determination, the sera were diluted 1:400, while the IgA antibodies specific for bacteria were detected in sera diluted 1:50.

\section{Immunolabeling and flow cytometry analysis}

The inguinal lymph nodes were isolated from both non-immunized and immunized rats. Individual cell suspensions were adjusted to $1 \times 10^{7}$ cells $/ \mathrm{ml}$ and $100 \mu 1$ of each cell suspension was labeled with anti-CD3-biotin antibody (Clone G4.18) followed by Streptavidin-FITC and anti-CD26-PE antibody (Clone OX-61). All antibodies were purchased from BD Pharmingen (San Diego, CA, USA). Immunolabeling was performed at $4{ }^{\circ} \mathrm{C}$ for 30 minutes. Samples (a total of $1 \times 10^{4}$ 
flow cytometric events) were analyzed on a FACScan flow cytometer (Cell Quest software, Becton Dickinson).

\section{Statistical analysis}

The quantitative data obtained were analyzed by two-factor ANOVA: strain $(\mathrm{DA}, \mathrm{AO}) \times$ time (day 0 , day 7 , day 21 ) for the levels of anti-E. coli antibodies; and strain $(\mathrm{DA}, \mathrm{AO}) \times$ immunization $(\mathrm{CFA}$, IFA, E. coli/CFA, E. coli/IFA) for the changes in the percentage of $\mathrm{CD}^{+} \mathrm{CD} 26^{+}$cells in inguinal lymph nodes, followed by Bonferroni as post-hoc test if appropriate. Strain differences in the percentages of $\mathrm{CD}^{+}$and $\mathrm{CD}^{+} \mathrm{CD}^{2} 6^{+}$cells in the lymph nodes of non-immunized rats were determined by Student's $t$-test. A $p$ value of less than 0.05 was considered significant. All analyses were performed by GraphPad PRISM-version 5.

\section{Results}

Clinical signs of arthritis following the immunization with CFA and IFA

Animals of both strains were examined daily for the appearance of clinical signs of arthritis on fore leg paws and hind paws for 42 days post immunization with CFA and IFA. In DA rats clinical signs of arthritis appeared on day 13 and day 15 following immunization with CFA and IFA, respectively, and all rats recovered by day 34 (Fig. 1A). Intense foot swelling was accompanied by frequent arthritic nodules in DA rats immunized with CFA, while immunization with IFA induced lower grade finger edema in two animals and no clinical signs of arthritis in three animals (Fig. 1B). The incidence of clinical signs of arthritis is shown in Figure 1C. Clinical signs of arthritis were not observed in AO rats immunized with CFA or IFA

\section{Humoral immune response to E. coli following}

the immunization with CFA and IFA

We have shown previously the presence of anti-E. coli $\mathrm{IgG}$ antibodies in the sera of non-immunized rats of both DA and AO strains, and this IgG priming was observed against a limited repertoire of $E$. coli proteins [12]. In order to monitor the immune response to $E$. coli during inductive phase of arthritis, the 

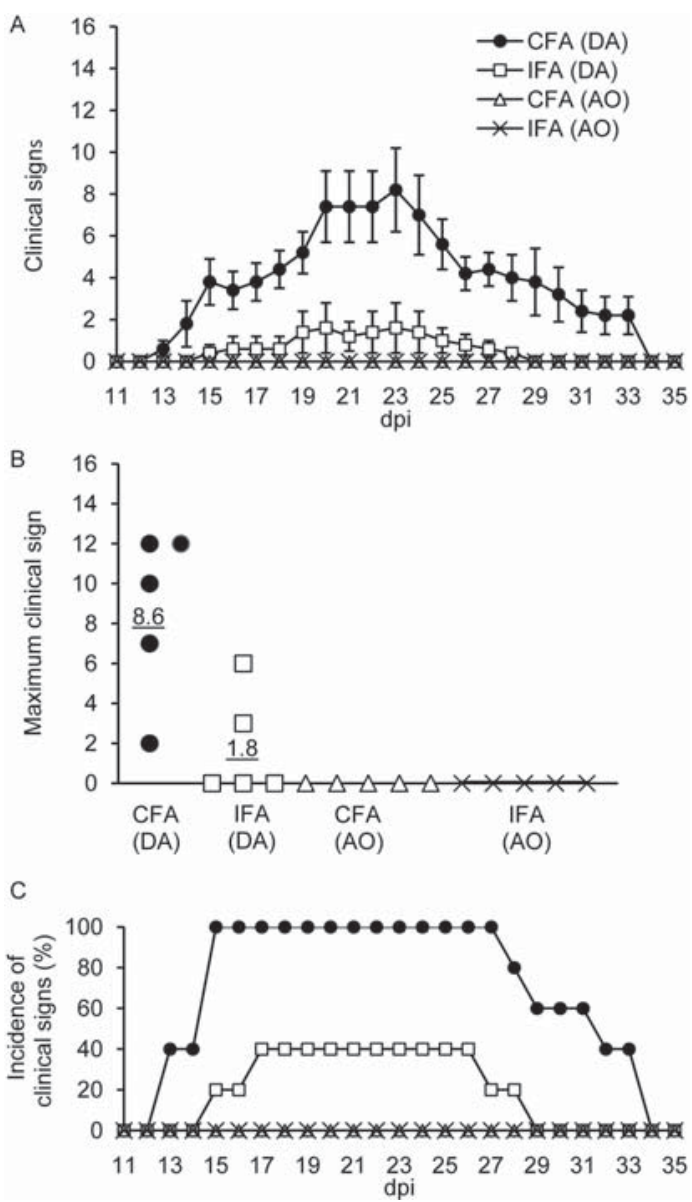

Figure 1. Clinical signs of arthritis (mean \pm SEM). (A), individual maximum clinical sign and corresponding means (B), and the incidence of clinical signs (C) in DA and AO rats following immunization with CFA or IFA. The number of rats was 5 per group

sera obtained on day 14 after immunization with CFA and IFA were examined for the presence anti-E. coli IgG antibodies by immunoblot.

On day 14 after immunization with IFA and CFA very weak anti-E. coli IgG binding levels were detected in sera of AO rats (Fig. 2A). Conversely, antibodies against $E$. coli proteins of molecular mass $\sim 28 \mathrm{kDa}$ were found in DA rats, which were immunized with CFA and developed signs of disease (Fig. 2A). Following complete recovery from the arthritis, a significant drop in IgG binding to E. coli protein extracts was observed in DA rats (day 42), while the sera of AO rats continued to show no significant reactivity (Fig. 2B). 


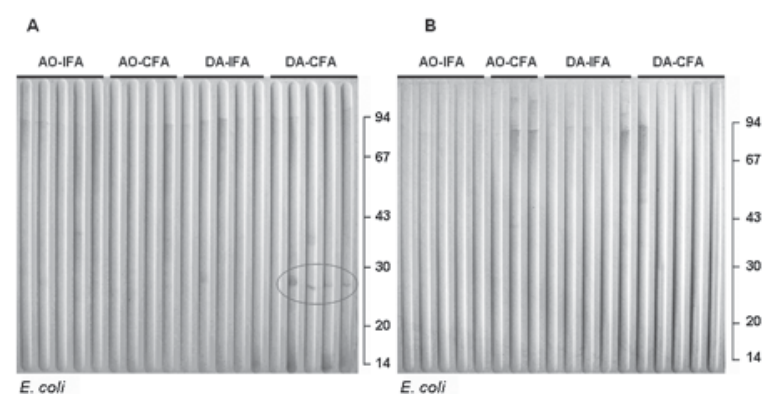

Figure 2. Western blot analysis of IgG binding to $E$. coli proteins in sera of AO and DA rats immunized with CFA and IFA on day 14 (A) and day 42 (B). Sphere contour highlights bands for IgG antibodies recognizing $E$. coli proteins of molecular mass $\sim 28 \mathrm{kDa}$

The effect of pre-immunization with $\mathrm{E}$. coli on humoral immune response to E. coli following the immunization with CFA and IFA

Anti-E. coli antibodies of all classes were detected in the sera obtained on day 0 in all experimental groups of DA and AO rats (Fig. 3). Before immunization with CFA or IFA (day 0) animals from groups $E$. coli/CFA and $E$. coli/IFA already had high levels of serum IgM, IgG2a and IgG2b class antibodies specific for $E$. coli, while the level of IgA antibodies was considerably lower. As expected, animals that were immunized with $E$. coli, and then received CFA or IFA, had significantly higher levels of antibodies of all three classes compared to animals that received only CFA or IFA, at all time points tested. By contrast, marked differences were observed in anti-E. coli $\operatorname{IgM}, \operatorname{IgG} 2 \mathrm{a}, \operatorname{IgG} 2 \mathrm{~b}$ and IgA antibody levels between the two rat strains following the specified treatments. Not taking into account the absolute value of the level of antibodies, there are noticeable trends in the kinetics of antibody production between the strains. The sera of DA rats contained almost twice the level of antibodies (IgM, IgG2a, IgG2b) compared to the AO strain. The differences were even more pronounced between the strains' IgG2a and IgG2b antibodies classes on day 7 and day 21. On the other hand, the specific antibody levels in AO rats' sera did not significantly change during the observed period. IgA antibodies were detected at low values, but were at a higher level in AO rats strain when compared to DA rats. Statistical analyses of anti$E$. coli antibody levels within particular subclass of antibody revealed significant interaction of factors, strain $\times$ time ( $p$ values for the interaction are shown in the graphs, Fig. 3). Similar changes in the level of $\operatorname{IgA}$ antibodies following immunization were observed in $E$. coli/IFA group of DA and AO rats. Namely, the level of $\operatorname{IgA}$ antibodies rise on day 7 and decline on day 21 in both rat strains (the significant main effect of time, $p<0.001$ ). However, at all time points examined, the 
CFA

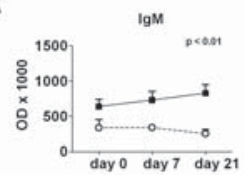

IFA

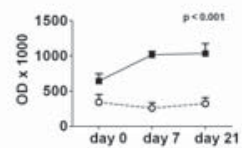

E. coli / CFA

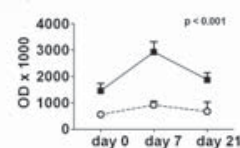

E. coli / IFA

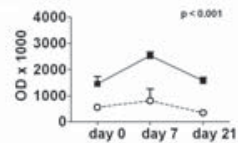

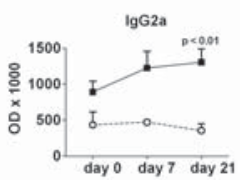
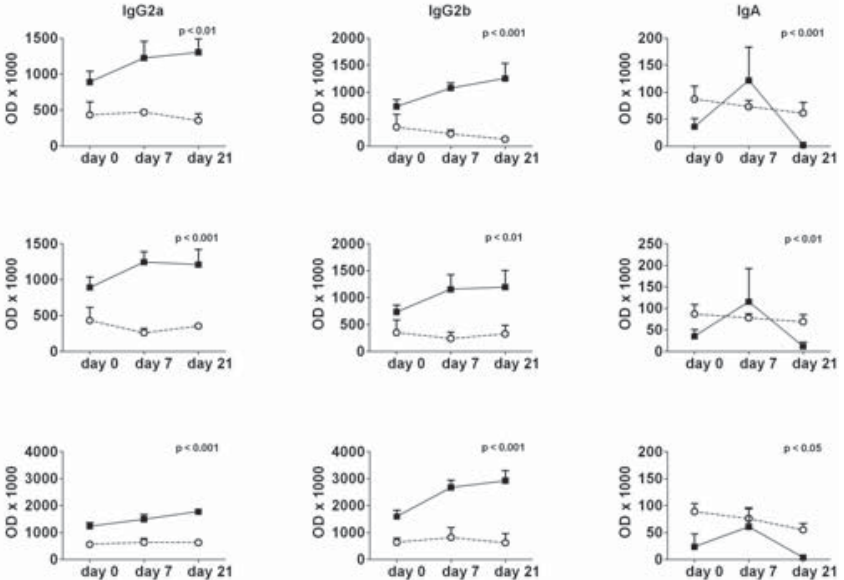

Figure 3. Anti- $E$. coli antibody levels of $\operatorname{IgM}, \operatorname{IgG} 2 \mathrm{a}, \operatorname{IgG} 2 \mathrm{~b}$ and $\operatorname{Ig} \mathrm{A}$ isotypes in sera of DA (black squares) and $\mathrm{AO}$ (white circles) rats immunized with CFA, IFA, E. coli/CFA or E. coli/IFA on day 0 , day 7 and day 21, quantified by ELISA. The number of sera samples was 6 per group. The results are expressed as $\mathrm{OD}_{492} \times 1000($ mean $+\mathrm{SD})$. $\mathrm{P}$ value for the statistically significant interaction of factors (strain $\times$ time) is shown in the top right corner of each graph

level of these antibodies was higher in AO rat's sera in comparison with DA rats sera (the significant main effect of strain, $p<0.001$ ).

The effect of pre-immunization with E. coli on T lymphocytes activation in inguinal lymph nodes from rats immunized with CFA or IFA

No strain difference in proportion of $\mathrm{CD}^{+}$cells in the lymph nodes of nonimmunized rats was observed (Fig. 4A). However, non-immunized AO rats exhibited higher percentage of $\mathrm{CD}^{+} \mathrm{CD} 26^{+}$cells in the inguinal lymph nodes in comparison with non-immunized DA rats, $p<0.001$ (Fig. 4B). Consequently, the strain difference in the activation of $\mathrm{CD}^{+}$lymphocytes following different regiments of immunization was estimated by the change of the percentage of $\mathrm{CD}^{+} \mathrm{CD}^{2} 6^{+}$cells relative to non-immunized control of each strain. Immunization with CFA or IFA increased the percentages of $\mathrm{CD}^{+} \mathrm{CD} 26^{+}$cells in inguinal lymph nodes of DA rats regardless of the pre-immunization with E. coli (Fig. 4C). On the contrary, decreased percentages of $\mathrm{CD}^{+} \mathrm{CD}^{2} 6^{+}$cells were observed in 
A

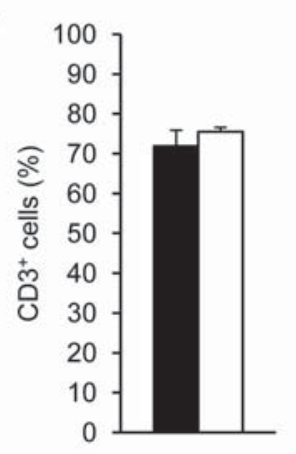

B

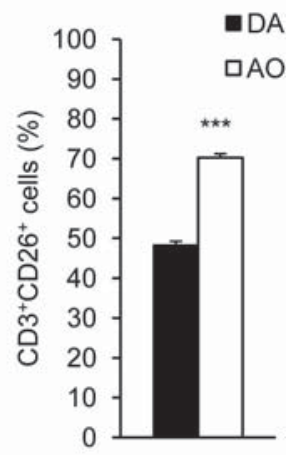

C

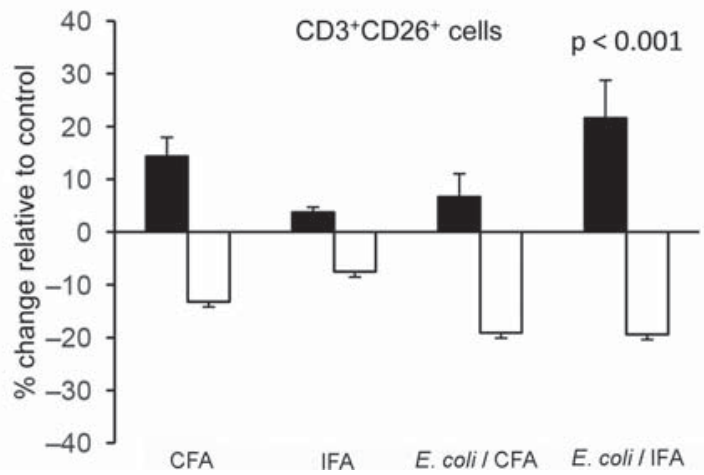

Figure 4. The percentages of $\mathrm{CD}^{+}$cells $(\mathrm{A})$ and $\mathrm{CD}^{+} \mathrm{CD} 26^{+}$cells $(\mathrm{B})$ in inguinal lymph nodes of non-immunized DA and $\mathrm{AO}$ rats. Changes in the percentage of activated $\mathrm{CD}^{+} \mathrm{CD} 26^{+}$cells in inguinal lymph nodes of rats immunized with CFA, IFA, E. coli/CFA or E. coli/IFA on day 21 relative to non-immunized control (C). The results are expressed as mean+SEM.

The number of animals was 6 per group. Statistically significant differences:

$* * * p<0.001, t$-test; and $p<0.001$, interaction of factors (strain $\times$ immunization), two-factor ANOVA

inguinal lymph nodes of immunized $\mathrm{AO}$ rats when compared to corresponding non-immunized control. Statistical analyses of the percentages of change of $\mathrm{CD}^{+} \mathrm{CD}^{2} 6^{+}$cells following immunization revealed significant interaction of factors, strain $\times$ treatment, $p<0.001$ (Fig. 4C).

\section{Discussion}

The findings published earlier speculated about the possible involvement of E. coli in pathogenesis of RA, primarily due to cross-reactivity between the peptide sequences present in its Heat shock protein (Hsp), DnaJ protein and the se- 
quences that were associated with susceptibility to RA [17]. However, no increased levels of anti-E. coli antibodies were found in patients compared to healthy individuals in numerous studies. Newkirk et al. reported the increased levels of IgM antibodies to E. coli in early rheumatoid factor-positive RA [18]. Following immunization with CFA and IFA, we have detected anti-E. coli antibody of IgG class in sera of both DA and AO rats, which differed in respect to their specificity, quantity and kinetics. Specifically, the presence of antibodies specific for the protein of molecular weight of $\sim 28 \mathrm{kDa}$ in sera of DA rats immunized with CFA suggested its association with the experimental arthritis.

It is well established that Hsps are the prominent targets of the immune response during the course of experimental arthritis. Bacterial heat shock proteins, primarily Hsp60 have been shown to be highly immunogenic molecules, able to activate a large number of T-cells. Hsp60 and Hsp70 recognition by T-cells and antibodies was implicated in numerous autoimmune inflammatory diseases [19].

It was shown that $E$. coli heat shock proteins, GroEL (molecular weight of $60 \mathrm{kDa}$ ) and GroES (molecular weight about $15 \mathrm{kDa}$ ) could act jointly to form the so-called GroE complex, twisting and help protein folding end protein subunits [20].

Our results point out that IgG antibodies to proteins of molecular weights $60 \mathrm{kDa}$ and $15 \mathrm{kDa}$ were not present in sera of our experimental rats. Even though we have used the whole $E$. coli protein extract and not the individual purified components such as a specific Hsp in our assays, the involvement of other Hsps cannot be excluded. It is recognized that both prokaryotic and eukaryotic cells produce a group of proteins with molecular mass of 15 to $42 \mathrm{kDa}$, designated as small heat shock proteins (sHsp) [21]. Some data are available supporting the proposal that disparate immune responses to Hsp are involved in different phases of arthritic disease [22]. It would certainly be important to investigate whether these antibodies may be regarded as diagnostic markers of arthritis or if they could also have a more prominent role, exhibiting a modulatory effect on the disease.

In the aim to further investigate humoral immune response to selected antigens of commensal flora, we decided to immunize animals with their own $E$. coli, and then induce the disease. It should be noted that pre-immunization with $E$. coli did not influence the incidence and the clinical signs of arthritis assessed until day 21 after immunization with CFA and IFA (data not shown) in DA rats, while none of AO rats developed the arthritis. Literature data show that the exposure of mice/rats to certain bacteria can actually induce protection from, rather than development of a disease. It has been shown that E. coli can render germ-free rats resistant to subsequently induced AA [23]. Also, accumulating 
evidence suggests that resistance to AA was due to the protective effect of antibodies specific for some Hsps. Ulmansky et al. concluded that Hsp, besides containing pathogenic $\mathrm{T}$ cell epitopes in $\mathrm{AA}$, also contains protective $\mathrm{B}$ cell epitopes exposed on its surface, and that natural and acquired resistance to AA is associated with the ability to respond to these epitopes [24]. In this case, it would suggest a possibility that our genetically susceptible DA rat strain is unable to respond to protective epitopes adequately. Another possible reason is the very nature of bacterial antigen used. It has been reported that Hsp, including minor subfamilies could protect against arthritis, whereas some other conserved bacterial proteins do not [25]. At last, the route of administration of potentially protective immunogen seems to be very important. Cobelens et al. reported that oral treatment with Hsp65 during the ongoing disease significantly reduced the activity of adjuvant-induced arthritis [26].

When examining the levels and strain distribution of different classes of antibodies we have discovered high production of $E$. coli-specific antibodies primarily in DA rats. Namely, the sera of diseased DA rats contained much higher levels of antibodies (IgM, IgG2a, IgG2b) compared to the AO strain. These findings are the extension of results in our previous work (without arthritis induction) which pointed out that immune response to own E. coli in AO rats reflected in weaker antibody production in combination with higher $\mathrm{CD}^{+}$cells proliferation compared to DA rats are indicative of suppressive immune mechanisms directed to these bacterial antigens.

Higher production of E. coli-specific antibodies in DA rats coincided with the peak of the disease (day 21) and were predominantly of IgG2b class in the rat immune system IgG1 and IgG2a antibodies are associated with a Th2-type response, while the IgG2b subclass is associated with a Th1-type response [27-29]. While the CFA and IFA were causing comparable levels of $\operatorname{IgG} 2 \mathrm{a}$ and $\operatorname{IgG} 2 \mathrm{~b} E$. coli-specific antibodies, suggesting mixed Th1/Th2 type of immune response, the pre-immunization with $E$. coli skewed the immune response toward promoting the Th1-like response pattern.

This finding suggests the need for more detailed insight into the specific alterations of the immune response caused by IFA and CFA. It is generally accepted that the CFA and IFA act to form a depot at the injection site, thus prolonging the duration of release of the antigen and its interactions with antigen presenting cells. Thereby they provide a complex set of signals for non-specific branch of the immune system, resulting in altered cell proliferation and differentiation of leukocytes. The effects of IFA/CFA include a fast uptake of adjuvant components by the dendritic cells, enhanced phagocytosis, secretion of cytokines by mononuclear phagocytes, and passing the activation and proliferation of $\mathrm{CD}^{+}$lymphocytes. In models where administration of IFA or CFA causes 
autoimmune disease in absence of intentionally added autoantigen, i.e. AIA and OIA (as used in our work), the polyclonal activation of lymphocytes is probably the crucial event [30]. In case of CFA, the cross-reactivity of antimycobacterial antibodies or T-cell receptors with epitopes of host proteins is considered the most probable mechanism. On the other hand, the ability of oil adjuvant to induce the disease could be attributed to breaking of peripheral tolerance and activation of constitutively present arthritogenic T-cell clones [30]. Activated T lymphocytes produce sets of different lymphokine combinations specific for type 1 or type 2 helper activity; while the immunization with IFA favors Th2, the immunization with CFA favors Th1 responsiveness [31]. In our experiments, the immunization with CFA and IFA caused the increase in production of anti-E. coli antibodies of IgG2a and IgG2b classes, respectively. Clearly, a very complex mechanism underlying the pathogenesis of adjuvant arthritis creates the environment in which the disregulation of cytokine profile influenced the humoral immune response we measured. In any case, further understanding of the CFA and IFA mode of action in induction of adjuvant arthritis is needed to be able to unambiguously define key elements in the onset and disease development.

The role of CD26/DPIV in autoimmune diseases has been widely studied. The increased number of peripheral T cells expressing CD26 was demonstrated in RA patients [32]. On the other hand, in plasma of RA patients the activity of this enzyme as antigen CD26 was decreased, as well as in plasma of animals with experimental arthritis [32]. Reduced levels of CD26 are associated with the severity of inflammation. However, other studies have shown that pharmacological inhibition of this enzyme stops the progression of the disease. Moreover, a number of in vitro and in vivo studies have used inhibitors of this molecule, highlighting CD26/DPIV as a potential target for the immunosuppressive therapy [33, 34]. The relative role of CD26 in RA is not yet apparent. It is unclear whether the level of this enzyme may affect inflammation over the course of RA, or whether the expression of this enzyme may be decreased in inflammatory arthritis.

In our study non-immunized animals of both rat strains, exhibited approximately equal numbers of $\mathrm{CD}^{+}$cells in the inguinal lymph nodes, but the number of $\mathrm{CD}^{+} \mathrm{CD}^{2} 6^{+}$cells was significantly higher in $\mathrm{AO}$ rats. The difference can be explained by their genetic background, which is significantly different in terms of expression of CD26 molecules. In general, the ability of T cells to regulate the level of membrane CD26 expression seems to be a specific feature of T cells, and is not observed with endothelial and renal cells, where CD26 is constitutively produced and its membrane level is relatively constant. This suggests that the location can be critical, and that locally present peptides can be sensitive to degradation by CD26/DPIV expressed on T-cells [35]. In our case, it could mean that the inguinal lymph nodes of $\mathrm{AO}$ rats provide a favorable milieu for active degra- 
dation of bioactive mediators; vice versa, the reduced numbers of $\mathrm{CD}^{+} \mathrm{CD} 26^{+}$ found in DA rats may be responsible for the autocrine defect in degradation of these mediators. Furthermore, it was shown that proteins and peptides that are part of the repertoire of biological constituent associated with CD26/DPIV can function as DPIV inhibitors in mice [36]. Several reports emphasize the importance of this marker as an inhibitory receptor that can serve as a target for ligands that block the enzyme activity and inhibit $\mathrm{T}$ cell activation and Th1-mediated immunity [33].

Immunization with CFA and IFA or pre-immunization with E. coli did not affect the percentage of T cells expressing CD26 in DA rats compared to intact animals. The percentage of positive cells was determined in the inguinal lymph nodes isolated on day 21 after immunization. It is possible that the percentage of positive cells would differ between the groups in other time points. It is well established that the expression of pro-inflammatory cytokines (TNF, IFN- $\gamma$, IL-2 and IL-17) increases in the inguinal lymph nodes in the early stages of AA [37]. The expression of these cytokines is transient, with the exception of IFN- $\gamma$, showing secondary growth later in the course of the disease (from day 17 onwards). Also, it was suggested that the initial increase in IFN- $\gamma$ occurs within pro-inflammatory response and that the subsequent increase may reflect the activation of regulatory T cells [37]. Thus, it is possible that even at the peak of the disease, a significant change in the population of T cells might be taking place; it is only that within the limited time period available we might have missed the narrow window of opportunity to detect these subtle differences between the experimental groups.

In $\mathrm{AO}$ rats, immunization with CFA decreased the percentage of $\mathrm{CD}^{+} \mathrm{CD} 26^{+}$cells relative to non-immunized control, whereas pre-immunization with $E$. coli diminished it only in comparison with animals immunized with IFA. These results can be viewed in light of the fact that CD26 expression increases after $\mathrm{T}$ cell activation [38] and continues to play a critical role in enabling the activated $\mathrm{T}$ cell to move into the extravascular space and consequently to the place of inflammation. Since AO rats are the arthritis resistant strain, we would like to suggest a possibility that, among other, this mechanism could contribute to prevention of inflammatory lesions in this strain.

\section{Conclusion}

Taken together, antibodies against E. coli proteins of molecular mass $\sim 28 \mathrm{kDa}$ were found in DA rats after immunization with CFA and IFA, during the inductive phase of arthritis. Following resolution of the disease, the examined 
sera have shown no significant reactivity to $E$. coli proteins. Also, CFA and IFA caused high production of $\operatorname{IgM}$, IgG2a and $\operatorname{IgG} 2 \mathrm{~b}$ anti-E. coli antibodies in DA rats, which coincided with the peak of the disease and immunization with own $E$. coli enhanced this effect. On the other hand, the pre-immunization with $E$. coli did not influence the incidence and the clinical signs of arthritis, as well as the activation of $\mathrm{T}$ cells in the draining inguinal lymph nodes of DA rats.

Generally, elevated level of antibodies to E. coli antigens, as a hyper-responsive immunological response to examined bacteria was found in arthritissusceptible DA rats and not in arthritis-resistant AO rats. The correlation between serologic response to commensal flora and susceptible rat's genetic background may contribute to the marked differences in the immune reactivity of $\mathrm{AO}$ and DA rats and may be of significance in further understanding of the role of humoral immunity in the pathogenesis of autoimmune arthritis. Our results suggest that, at least in DA rats, basal and immunization-induced elevated immune response to $E$. coli antigens, although not decisive for disease susceptibility, probably represents a priming factor that sets a scene for subsequent immune events leading to a predisposition to arthritis induction.

\section{Acknowledgement}

This work was supported by the Ministry of Education, Science and Technological Development Republic of Serbia (Grant No. 175050).

\section{References}

1. Lanchbury, J.S.: The HLA association with rheumatoid arthritis. Clin Exp Rheumatol 10, 301-304 (1992).

2. Bridges, S.L. Jr.: The genetics of rheumatoid arthritis: influences on susceptibility, severity, and treatment response. Curr Rheumatol Rep 1, 164-171 (1999).

3. Corrigall, V.M., Bodman-Smith, M.D., Fife, M.S., Canas, B., Myers L.K., Wooley, P., Soh, C., Staines, N.A., Pappin, D.J., Berlo, S.E., van Eden, W., van Der Zee, R., Lanchbury, J.S., Panayi, G.S.: The human endoplasmic reticulum molecular chaperone BiP is an autoantigen for rheumatoid arthritis and prevents the induction of experimental arthritis. J Immunol 166, 1492-1498 (2001).

4. Jawaheer, D., Gregersen, P.K.: Rheumatoid arthritis. The genetic components. Rheum Dis Clin North Am 28, 1-15 (2002).

5. Christen, U., von Herrath, M.G.: Infections and autoimmunity-good or bad? J Immunol 174, 7481-7486 (2005). 
6. Tlaskalova-Hogenova, H., Tučkova, L., Lodinova-Žadnikova, R., Štepankova, R., Cukrowska, B., Funda, D.P., Striž, I., Kozakova, H., Trebichavsky, I., Sokol, D., Rehakova, Z., Šinkora, J., Fundova, P., Horakova, D., Jelinkova, L., Sanchez, D.: Mucosal immunity: Its role in defense and allergy. Int Arch Allergy Immunol 128, 77-89 (2002).

7. Kverka, M., Tlaskalova-Hogenova, H.: Two faces of microbiota in inflammatory and autoimmune diseases: triggers and drugs. APMIS 121, 403-421 (2013).

8. Scher, J.U., Abramson, S.B.: The microbiome and rheumatoid arthritis. Nat Rev Rheumatol 7, 569-578 (2011).

9. Tlaskalova-Hogenova, H., Štepankova, R., Hudcovic, T., Tučkova, L., Cukrowska, B., Lodinova-Žadnikova, R., Kozakova, H., Rossman, P., Bartova, J., Sokol, D., Funda, D.P., Borovska, D., Rehakova, Z., Šinkora, J., Hofman, J., Drastich, P., Kokešova, A.: Commensal bacteria (normal microflora), mucosal immunity and chronic inflammatory and autoimmune diseases. Immunology Lett 93, 97-108 (2004).

10. Dimitrijević, M., Laban, O., Djurić, V.J., Stanojević, S., Miletić, T., Kovacevič-Jovanović, V., Todorović, Č., Radulović, J.: Behavior and severity of adjuvant arthritis in four rat strains. Brain Behav Immun 15, 255-265 (2001).

11. Kovačevic-Jovanović, V., Mitić, K., Stanojević, S., Miletic, T., Vujić, V., Dimitrijević, M.: Production of $\mathrm{H}_{2} \mathrm{O}_{2}$ and $\mathrm{NO}$ by rat peritoneal macrophages in response to gut commensal bacteria. Acta Veterinaria 59, 111-122 (2009).

12. Kovačević-Jovanović, V., Miletić, T., Stanojević, S., Mitić, K., Dimitrijević, M.: Strain differences in the humoral immune response to commensal bacterial antigens in rats. Acta Microbiol Immunol Hung 60, 271-288 (2013).

13. Holmdahl, R., Goldschmidt, T.J., Kleinau, S., Kvick, C., Jonsson, R.: Arthritis induced in rats with adjuvant oil is a genetically restricted, T-cell dependent autoimmune disease. Immunology 76, 197-202 (1992).

14. Griffiths, M.M., DeWitt, C.W.: Immunogenetic control of experimental collagen-induced arthritis in rats. II. ECIA susceptibility and immune response to type II collagen (CALF) are linked to RT1. J Immunogenet 8, 463-470 (1981).

15. Laemmli, U.K.: Cleavage of structural proteins during the assembly of the head of bacteriophage T4. Nature 227, 680-685 (1970).

16. Towbin, H., Stachlin, T., Gordon, J.: Electrophoretic transfer of proteins from polyacrylamide gels to nitro-cellulose sheets: procedures and some applications. Proc Natl Acad Sci U S A 76, 4350-4354 (1979).

17. Albani, S., Tuckwell, J., Esparza, D., Carson, D., Roudier, J.: The susceptibility sequence to rheumatoid arthritis is a cross-reactive B-cell epitope shared by Escherichia coli heat shock protein dnaJ and the histocompatibility leucocyte antigen DRB10401 molecule. J Clin Investig 89, 327-331 (1992).

18. Newkirk, M.M., Goldbach-Mansky, R., Senior, B.W., Klippel, J., Schumacher, H.R, Jr, El-Gabalawy, H.S.: Elevated levels of IgM and IgA antibodies to Proteus mirabilis and IgM antibodies to Escherichia coli are associated with early rheumatoid factor (RF)positive rheumatoid arthritis. Rheumatology 44, 1433-1441 (2005).

19. Wallin, R.P., Lundqvist, A., More, S.H., von Bonin, A., Kiessling, R., Ljunggren, H.G.: Heat-shock proteins as activators of the innate immune system. Trends Immunol 23, 130 135 (2002).

20. Zugel, U., Kaufmann, S.H.: Role of heat shock proteins in protection from and pathogenesis of infectious diseases. Clin Microbiol Rev 12, 19-39 (1999). 
21. Desai, N.S., Agarwal, A.A., Uplap, S.S.: HSP: evolved and conserved proteins, structure and sequence studies. Int J of Bioi Res 2, 67-87 (2010).

22. Huang, M.N., Yu, H., Moudgil, K.D.: The involvement of heat-shock proteins in the pathogenesis of autoimmune arthritis: a critical appraisal. Semin Arthritis Rheum 40, 164-175 (2010).

23. Kohashi, O., Kohashi, Y., Takahashi, T., Ozawa, A., Shigematsu, N.: Suppressive effect of Escherichia coli on adjuvant-induced arthritis in germ-free rats. Arthritis Rheum 29, 547-553 (1986).

24. Ulmansky, R., Cohen, C.J., Szafer, F., Moallem, E., Fridlender, Z.G., Kashi, Y., Naparstek, Y.: Resistance to adjuvant arthritis is due to protective antibodies against heat shock protein surface epitopes and the induction of IL-10 secretion. J Immunol 168, 6463-6469 (2002).

25. van Eden, W., Wendling, U., Paul, L., Prakken, B., van Kooten, P., van der Zee, R.: Arthritis protective regulatory potential of self-heat shock protein cross-reactive T cells. Cell Stress \& Chaperones 5, 452-457 (2000).

26. Cobelens, P.M., Heijnen, C.J., Nieuwenhuis, E.E., Kramer, P.P., van der Zee, R., van Eden, W., Kavelaars, A.: Treatment of adjuvant-induced arthritis by oral administration of mycobacterial Hsp65 during disease. Arthritis Rheum 43, 2694-2702 (2000).

27. Bowman, L.M., Holt, P.G.: Selective enhancement of systemic Th1 immunity in immunologically immature rats with an orally administered bacterial extract. Infect Immun 69, 3719-3727 (2001).

28. Saoudi, A., Kuhn, J., Huygen, K., de Kozak, Y., Velu, T., Goldman, M., Druet, P., Bellon, B.: TH2 activated cells prevent experimental autoimmune uveoretinitis, a TH1-dependent autoimmune disease. Eur J Immunol 23, 3096-3103 (1993).

29. Wykes, M., Pombo, A., Jenkins, C., MacPherson, G.G.: Dendritic cells interact directly with naive B lymphocytes to transfer antigen and initiate class switching in a primary T-dependent response. J Immunol 161, 1313-1319 (1998).

30. Shibaki, A., Katz, S.I.: Induction of skewed Th1/Th2 T-cell differentiation via subcutaneous immunization with Freund's adjuvant. Exp Dermatol 11, 126-134 (2002).

31. Billiau, A., Matthys, P.: Modes of action of Freund's adjuvants in experimental models of autoimmune diseases. J Leukoc Biol 70, 849-860 (2001).

32. Busso, N., Wagtmann, N., Herling, C., Chobaz-Péclat, V., Bischof-Delaloye, A., So, A., Grouzmann, E.: Circulating CD26 is negatively associated with inflammation in human and experimental arthritis. Am J Pathol 66, 433-442 (2005).

33. Preller, V., Gerber, A., Wrenger, S., Togni, M., Marguet, D., Tadje, J., Lendeckel, U., Röcken, C., Faust, J., Neubert, K., Schraven, B., Martin, R., Ansorge, S., Brocke, S., Reinhold, D.: TGF-betal-mediated control of central nervous system inflammation and autoimmunity through the inhibitory receptor CD26. J Immunol 178, 4632-4640 (2007).

34. Reinhold, D., Kähne, T., Steinbrecher, A., Wrenger, S., Neubert, K., Ansorge, S., Brocke, S.: The role of dipeptidyl peptidase IV (DP IV) enzymatic activity in T cell activation and autoimmunity. Biol chem 383, 1133-1138 (2002).

35. Sedo, A., Duke-Cohan, J.S., Balaziova, E., Sedova, L.R.: Dipeptidyl peptidase IV activity and/or structure homologs: contributing factors in the pathogenesis of rheumatoid arthritis? Arthritis Res Ther 7, 253-269 (2005).

36. De Meester, I., Korom, S., Van Damme, J., Scharpé, S.: CD26, let it cut or cut it down. Immunol Today 20, 367-375 (1999). 
37. Bush, K.A., Walker, J.S., Lee, C.S., Kirkham, B.W.: Cytokine expression and synovial pathology in the initiation and spontaneous resolution phases of adjuvant arthritis: interleukin-17 expression is upregulated in early disease. Clin Exp Immunol 123, 487-495 (2001).

38. Ohnuma, K., Yamochi, T., Uchiyama, M., Nishibashi, K., Iwata, S., Hosono, O., Kawasaki, H., Tanaka, H., Dang, N.H., Morimoto, C.: CD26 mediates dissociation of tollip and IRAK-1 from caveolin-1 and induces upregulation of CD86 on antigen-presenting cells. Mol Cell Biol 25, 7743-7757 (2005). 